\title{
Método para captura e priorização de requisitos de futuros usuários de Habitações de Interesse Social
}

\author{
Method to capture and prioritize future users' \\ requirements of low-income housing
}

\author{
Aline Campelo Blank Freitas \\ Edar da Silva Añaña \\ Fábio Kellermann Schramm
}

\section{Resumo}

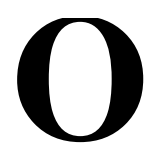

valor do produto, como percebido pelo usuário, envolve interações complexas entre escolhas que estes realizam, em face de um grande conjunto de atributos positivos e negativos. Nesse contexto, é possível destacar a ausência de um procedimento que aproxime o valor recebido pelo usuário do seu valor desejado. O objetivo geral deste trabalho é propor um método para captura e priorização de requisitos de usuários para subsidiar o processo de concepção e projeto de empreendimentos habitacionais de interesse social (EHIS), com base em um estudo de caso no âmbito do Programa Minha Casa Minha Vida - Entidades. Como estratégia de pesquisa optou-se pela Design Science Research. O trabalho foi dividido em três fases, além de uma revisão de literatura. Na fase exploratória, adaptou-se a técnica de análise conjunta baseada em escolhas, para a realidade da pesquisa. A fase de desenvolvimento contemplou as seguintes etapas: (a) captura dos requisitos; (b) hierarquização e priorização desses requisitos e; (c) relação entre os modelos de preferência, e os tipos de família dos futuros usuários de habitações de interesse social (HIS). Com base na última fase, de análise e reflexão, foi proposto um método para captura e priorização de requisitos de usuários, com vistas à disponibilização desses requisitos para subsidiar o processo de concepção e projeto de EHIS.

Palavras-chave: Gerenciamento de requisitos. Habitação de Interesse Social. Análise conjunta.

${ }^{1}$ Aline Campelo Blank Freitas IInstituto Federal Sul-Rio-Grandense Pelotas - RS - Brasil

${ }^{2}$ Edar da Silva Añaña Universidade Federal de Pelotas Pelotas - RS - Brasil

${ }^{3}$ Fábio Kellermann Schramm 3Universidade Federal de Pelotas Peltoas - RS - Brasil

Recebido em 23/11/20 Aceito em 04/03/21

\begin{abstract}
In construction, product value, from an end user's perspective, consists of complex choices between many positive and negative attributes. Moreover, there is a lack of methods that reduce the gap between received and intended value by the user. Thus, this research aims to propose a method to capture and prioritize end user requirements, to subsidize the conception and design phases of low-income housing projects, based on a case study carried out in the Minha Casa Minha Vida - Entidades Program (Brazil), using Design Science Research as the research method. The research was divided into three phases, in addition to a literature review. Firstly, in the Exploratory Phase, the Choice-based Conjoint Analysis Technique was adapted to the research context. Secondly, the Development Phase consisted of three steps: (a) user requirements' capture; (b) requirements' hierarchy and prioritization; and (c) relationship between Preference Models and end user families of further housing projects. Thirdly, in the Analysis and Reflection Phase, a method for capturing and prioritizing end user requirements was devised, aimed to help the conception and design process of low-income housing projects.
\end{abstract}

Keywords: Requirements management. Low-income housing. Joint analysis 


\section{Introdução}

Lançado em 2009, com o objetivo de reduzir o déficit habitacional brasileiro, que naquele momento alcançava 6,8 milhões de moradias (ECCONIT, 2020), o Programa Minha Casa Minha Vida (PMCMV) foi responsável pela contratação de 6,27 milhões de unidades habitacionais em todo o país até o ano de 2020 (BRASIL, 2020).

Entre as características do PMCMV, a Caixa Econômica Federal, operadora do programa, implementou, na tentativa de garantir espaço à participação da população beneficiária, o Trabalho Técnico Social (TTS) (CAIXA..., 2013b). O TTS abrange atividades de divulgação de informações sobre a intervenção, projetos de obras e trabalho social, além da preparação da entidade representativa dos moradores e os usuários para a ocupação da nova moradia, acompanhando o período de pós-ocupação do empreendimento (CAIXA, 2013a).

Entretanto, os recursos para a implantação desse trabalho somente são liberados após a contratação da obra, ou seja, a partir do momento em que o projeto já se encontra definido, não permitindo a participação dos futuros usuários nas etapas de desenvolvimento do projeto do empreendimento (MINEIRO; RODRIGUES, 2012).

De acordo com Baldauf (2013), muitos estudos foram desenvolvidos buscando aumentar a qualidade do ambiente construído, tendo como foco a geração de valor.

O valor do produto, como percebido pelo usuário, envolve interações complexas entre trade-offs que estes realizam, em face de um grande conjunto de atributos positivos, como a localização e a vizinhança, e negativos, como a presença de equipamentos urbanos e segurança, por exemplo (MIRON; FORMOSO, 2010).

Granja et al. (2009) salientam que, na maioria dos EHIS, como é o caso daqueles desenvolvidos no âmbito do PMCMV, os atributos preferenciais do usuário não são considerados na etapa de concepção, visto que não há um procedimento para aproximar o valor recebido pelo usuário do valor por ele desejado (GRANJA et al., 2009).

No contexto do PMCMV, o PMCMV-Entidades prevê a concessão de financiamentos a futuros usuários organizados de forma associativa por uma entidade organizadora (associação, cooperativa, sindicato, entre outras), com recursos provenientes do Orçamento Geral da União (OGU) e aportados ao Fundo de Desenvolvimento Social (FDS) (BRASIL, 2020).

Nessa forma de produção autônoma, denominada autogestão, os recursos financeiros são destinados diretamente à entidade organizadora, que se responsabiliza pelo desenvolvimento do projeto e posteriormente pela construção, com a ajuda de assessorias técnicas e fiscalização do poder público (KAPP; CARDOSO, 2013), descortinando-se, dessa forma, a possibilidade de envolver os futuros usuários ainda na etapa de concepção e projeto dos empreendimentos.

Santos, Kistmann e Fischer (2004) apontam que a falta de experiência das famílias em viver em uma casa adequada, comum às famílias beneficiadas pelo PMCMV, pode dificultar a expressão de suas reais necessidades. Assim, algumas técnicas, como o uso de entrevistas semiestruturadas, por si só, não permitem a captura completa dos requisitos, sendo oportuno o desenvolvimento e a implementação de outras técnicas, tanto para a captura como para o processamento dos requisitos (SANTOS; KISTMANN; FISCHER, 2004).

Aliado a isso, o que se pode perceber na maioria dos EHIS desenvolvidos no país é que suas moradias não atendem satisfatoriamente a diversidade de arranjos familiares brasileiros, uma vez que seus ambientes são normalmente subdimensionados, tornando-se insuficientes para acomodar o mobiliário e os equipamentos mínimos necessários para o funcionamento das residências (CONCEIÇÃO; IMAI; URBANO, 2015).

Lima et al. (2009) afirmam que a retroalimentação de informações provenientes da etapa de uso aos novos projetos pode se tornar possível, pela utilização de conceitos, modelos e abordagens investigados por seu potencial em termos de inovação na geração de valor em HIS, na busca por melhorar o processo de desenvolvimento de produto (PDP), em segmentos de mercado em que o foco tem sido apenas a redução de custos (LIMA et al., 2009).

Zinas e Jusan (2017) apontam que existem muitas abordagens sugeridas ou desenvolvidas para mensuração das preferências dos usuários, variando de simples questionamentos diretos aos respondentes até sofisticadas abordagens de medição. 
Nesse contexto, entre as técnicas para a captura de requisitos dos clientes, pode-se destacar a avaliação pósocupação (APO) (MIRON, 2008), que busca aferir o nível de satisfação dos usuários e o atendimento das suas necessidades, a partir do diagnóstico dos fatores positivos e negativos percebidos no ambiente construído ao longo de seu uso e que podem ser utilizados na retroalimentação de novos projetos (ROMÉRO; ORNSTEIN, 2003).

Entretanto, segundo Kowaltowski et al. (2006), o indicador satisfação do usuário deve ser utilizado com reserva, em questões relacionadas a EHIS, uma vez que estudos de APO realizados nesses tipos de empreendimentos, no Brasil, geralmente evidenciam níveis elevados de satisfação de seus usuários devido à situação precária contextual em que essas famílias viviam anteriormente.

Nesse mesmo sentido, em APO realizada por Blank-Freitas, Añaña e Schramm (2013), demonstrou-se que mesmo morando em uma casa com dimensões e compartimentos insuficientes para acomodação da família, percebeu-se a aceitação dos moradores à sua situação habitual, fruto de um processo mental de contentamento que provocou a mudança em suas preferências e a adaptação a uma situação viável.

Por outro lado, a técnica de análise conjunta (Conjoint Analysis), também conhecida como técnica da preferência declarada (State of Preference), permite testar pressupostos subjacentes às suas abordagens de medição (ZINAS; JUSAN, 2017), consistindo em apresentar diversas alternativas ao respondente para que uma seja escolhida, indicando a sua escolha preferida de atributos, em relação às demais alternativas (BRANDLI; HEINECK, 2005). A sua maior vantagem é permitir medir o comportamento de preferência e escolha de um produto ainda inexistente (ORZECHOWSKI, 2004).

Com base nisso, entende-se que o emprego da técnica de análise conjunta possa auxiliar na priorização dos requisitos de futuros usuários de HIS, contribuindo para o aumento do valor percebido pelo usuário, a partir da inserção de seus requisitos ainda na etapa de concepção e projeto de suas moradias.

Na construção civil, Brandli e Heineck (2005) utilizaram essa técnica para a realização de um estudo de mercado sobre a escolha habitacional de estudantes universitários. A pesquisa partiu de um conjunto de atributos, organizados em grupos, previamente fornecidos e explicados aos entrevistados, utilizando cartões que eram expostos de maneira aleatória, e pedindo para que o indivíduo escolhesse um atributo de sua preferência para cada grupo, formando assim seu conjunto de preferências (BRANDLI; HEINECK, 2005). Entretanto, esses atributos não foram capturados diretamente a partir de uma situação de uso da habitação, bem como os entrevistados não eram, necessariamente, futuros usuários das moradias.

Moraes (2017) utilizou a técnica para propor um método que possibilitasse a identificação de oportunidades de realocação de custos em projetos de empreendimentos habitacionais. Já Carvalho, Granja e Silva (2020) a utilizaram para identificar as preferencias declaradas pelos usuários com base na certificação AQUAHQE $^{\text {TM} 1}$, para investigar os valores sustentáveis desejáveis em HIS.

Assim, embora esses trabalhos tenham utilizado a técnica da preferência declarada (análise conjunta), foram desenvolvidos em contextos diferentes (moradia estudantil), ou preocuparam-se com outros aspectos relativos a valor no projeto (redução de custos e sustentabilidade), não tendo como foco a participação de futuros usuários no processo de concepção e projeto de HIS, possível pela configuração do PMCMVEntidades.

Assim, com base no acima exposto, o objetivo deste trabalho é propor um método para a captura e priorização de requisitos de usuários finais, com vistas à sua disponibilização para subsidiar o processo de concepção e projeto de EHIS produzidas em contextos similares.

\section{Gerenciamento de requisitos}

Ulrich e Eppinger (2000) apontam que a identificação das necessidades dos clientes ${ }^{2}$ deve ter seu próprio processo, por meio de cinco passos:

(a) coletar dados brutos dos clientes;

(b) interpretar os dados brutos em termos de necessidades dos clientes;

${ }^{1}$ AQUA-HQE ${ }^{T M}$ é uma ferramenta de classificação francesa que leva a níveis de certificação de acordo com questões ambientais consideradas na construção de um edifício (YUSOFF; WEN, 2014).

${ }^{2} \mathrm{O}$ termo cliente, ao invés de usuário, como vem sendo mencionado no texto, foi mantido, pois é o termo originalmente utilizado por Ulrich e Eppinger (2000). 
(c) organizá-las hierarquicamente, como necessidades primárias, secundárias e terciárias;

(d) estabelecer a importância relativa das necessidades; e

(e) refletir sobre os resultados e o processo.

Segundo Koskela (2000), a tradução dos requisitos do cliente em soluções de projeto estabelece uma forte relação com a geração de valor do ponto de vista do cliente final.

Uma vez que o gerenciamento dos requisitos tem como objetivo possibilitar uma melhor definição das soluções de projeto e uma maior agregação de valor ao produto, a entrega de valor requer um claro entendimento do que é desejado pelo cliente (MIRON, 2008). O foco na estratégia de entregar valor para o cliente depende da aprendizagem sobre esse cliente e sobre o que agrega valor para si (WOODRUFF; GARDIAL, 1996).

\section{Técnica de análise conjunta na estimativa da preferência do usuário}

Battesini e Caten (2005) definem análise conjunta (AC) tanto como um experimento, quanto como uma pesquisa de marketing, tendo como objetivo estimar a preferência do consumidor. $\mathrm{Na} \mathrm{AC}$, ao avaliar produtos ou serviços, reais ou hipotéticos, os respondentes realizam um trade-off entre atributos, inseridos em um conjunto previamente planejado. Assim, as avaliações dos respondentes permitem que seja gerado um modelo de preferência, que representa o comportamento do consumidor (BATTESINI; CATEN, 2005).

Do ponto de vista estatístico, Hair Junior et al. (2009) definem a análise conjunta como uma técnica multivariada, utilizada para compreender como os respondentes estabelecem preferências por quaisquer produtos, serviços ou ideias, baseada na premissa de que os clientes avaliam o valor de um objeto (real ou hipotético), combinando quantias separadas de valor fornecidas por cada atributo. Nesse sentido, pode-se estimar melhor suas preferências, julgando objetos formados por combinações de atributos (HAIR JUNIOR et al., 2009).

A vantagem desse tipo de análise é a habilidade de representar as preferências para cada indivíduo de maneira objetiva, com o intuito de auxiliar na identificação de suas necessidades, dar prioridade a essas necessidades e então traduzi-las na forma de estratégias reais (HAIR JUNIOR et al., 2009).

Devido ao número de atributos envolvidos e a demanda de uma tarefa de escolha mais realista, pesquisas recentes têm conduzido experimentos utilizando dois métodos conjuntos:

(a) análise conjunta adaptativa/autoexplicada, para lidar com muitos atributos; e

(b) análise conjunta baseada em escolhas, para fornecer tarefas de escolha mais realistas (HAIR JUNIOR et al., 2009).

Dessa forma, no presente trabalho adotou-se o método de análise conjunta baseada em escolhas, utilizada em outros estudos já referenciados, como os de Brandli e Heineck (2005), Moraes (2017) e Carvalho, Granja e Silva (2020).

\section{Método de pesquisa}

Os estudos realizados nesta pesquisa integram o trabalho desenvolvido no âmbito do projeto "Desenvolvimento de tecnologias sociais (ts) para a construção, recuperação, manutenção e uso sustentável de moradias, especialmente HIS, e para a redução de riscos ambientais", financiada com recursos da Finep. Este projeto foi desenvolvido a partir da formação, em 2011, da rede de pesquisa Morar.TS, da qual participam sete universidades brasileiras (UFRGS, UFPel, UFRJ, UFAL, UFCG, USP/São Carlos, UFMG), além da Fundação Osvaldo Cruz (Fiocruz).

A estratégia de pesquisa utilizada foi a Design Science Research, que se caracteriza por ser um método que estabelece e operacionaliza a pesquisa quando o objetivo desejado é um artefato ou uma recomendação (DRESCH; LACERDA; ANTUNES JÚNIOR, 2015).

Segundo Van Aken (2004), o principal papel da Design Science Research é gerar conhecimento para a concepção e desenvolvimento de um artefato, ou seja, um arranjo de elementos de um ambiente interno para alcançar objetivos em um determinado ambiente externo.

No caso da presente pesquisa, essa estratégia apresenta-se adequada, pois: 
(a) busca-se estabelecer e operacionalizar um método para contribuir para a solução do problema da ausência de inserção dos requisitos de futuros usuários no processo de concepção e projeto de HIS, a partir de um modelo prévio adaptado das técnicas de marketing para captura e priorização de requisitos; e

(b) gera conhecimento para a concepção e desenvolvimento de um método para captura e priorização dos requisitos dos usuários finais para subsidiar a concepção e projeto das HIS, avaliando e refinando a proposta (artefato).

Para tanto, a pesquisa foi dividida em quatro fases, relacionadas às etapas da Design Science Research, conforme apresentado por Vaishnavi, Kuechler e Petter (2019), apresentado na Figura 1:

(a) revisão de literatura, desenvolvida ao longo de todo o trabalho, como fluxo de contribuição do conhecimento;

(b) fase exploratória, que contemplou a conscientização do problema, e a sugestão de um modelo preliminar adaptado;

(c) fase de desenvolvimento, com a realização de uma APO e de um estudo de caso; e

(d) fase de análise e reflexão, com a avaliação e proposta do método supracitado.

A revisão de literatura buscou identificar em que medida futuros usuários estiveram inseridos no processo de concepção e projeto de EHIS ao longo da história dos programas habitacionais implementados até os dias atuais. Já na fase exploratória, a revisão de literatura teve como objetivo identificar um método adequado a ser testado como ferramenta para captura e priorização dos requisitos de futuros usuários, no subsídio ao processo de concepção e projeto de EHIS.

Após a seleção do método de análise conjunta baseada em escolhas, procedeu-se sua adaptação ao contexto e objetivo da pesquisa, qual seja, capturar e priorizar os requisitos de futuros usuários de HIS. Dessa forma, o delineamento do experimento para a aplicação da análise conjunta baseou-se na adaptação do modelo (e respectivos estágios) proposto por Hair Junior et al. (2009), conforme apresentado no Quadro 1, a seguir.

A fase de desenvolvimento foi dividida em duas subfases:

(a) realização de levantamento, por meio de um estudo de APO, que teve como objetivo a captura de requisitos que resultou na lista preliminar de atributos; e

(b) um estudo de caso, no qual foi realizada a captura, hierarquização e priorização dos requisitos de futuros usuários de HIS.

$\mathrm{Na}$ APO, foram caracterizados os programas e projetos habitacionais promovidos pela Prefeitura Municipal de Pelotas, no Rio Grande do Sul, com vistas a atender populações na faixa de renda de 0 a 3 saláriosmínimos, no total de 782 moradias, distribuídas em 12 áreas distintas da cidade.

Figura 1 - Delineamento da pesquisa

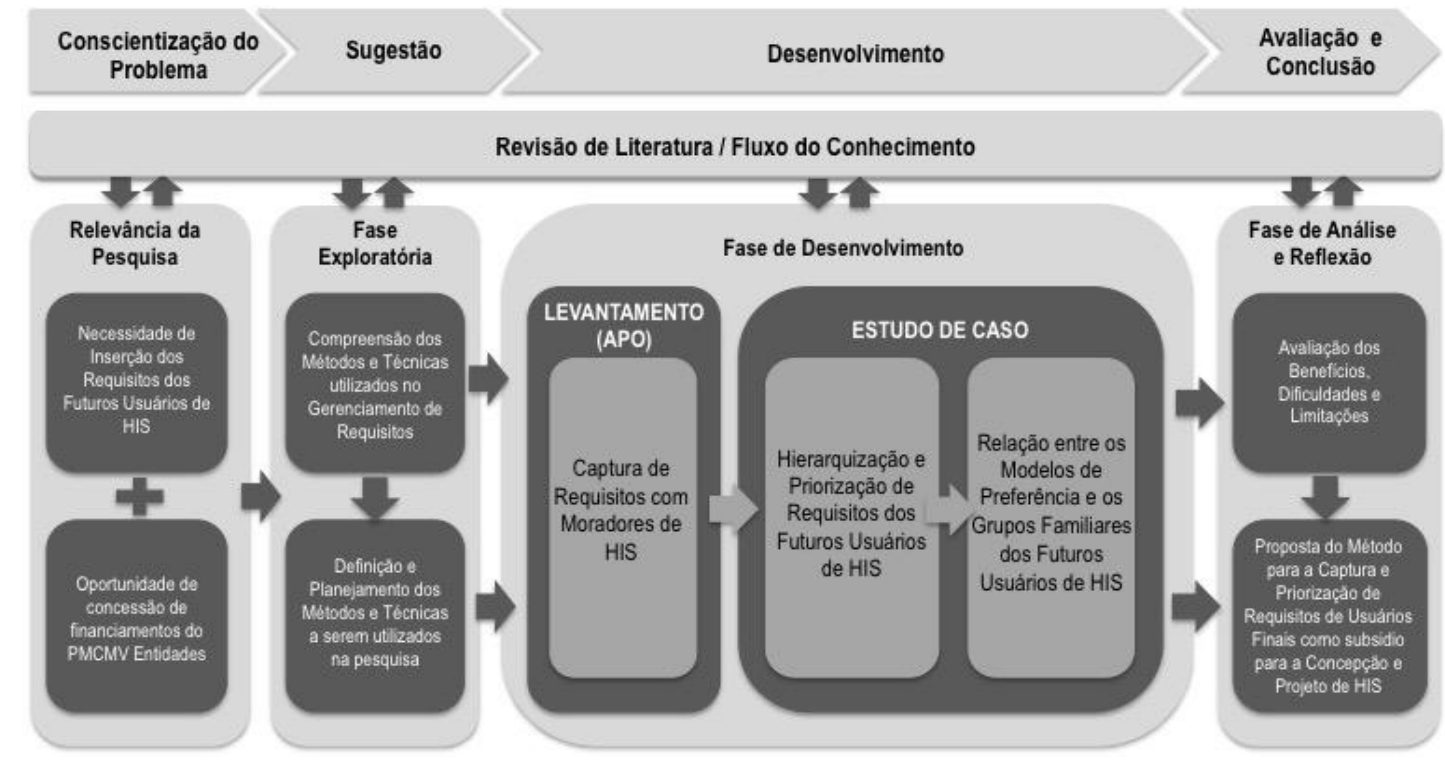


Quadro 1 - Delineamento do experimento, proposto por Hair Junior et al. (2009), adaptado à realidade da pesquisa

\begin{tabular}{|c|c|c|}
\hline Estágios & $\begin{array}{c}\text { Delineamento proposto por Hair } \\
\text { Junior et al. (2009) }\end{array}$ & $\begin{array}{c}\text { Delineamento adaptado à realidade da } \\
\text { pesquisa }\end{array}$ \\
\hline Estágio 1 & $\begin{array}{l}\text { Definição dos objetivos da análise } \\
\text { conjunta }\end{array}$ & $\begin{array}{l}\text { Hierarquização e priorização de requisitos } \\
\text { capturados no estudo exploratório }\end{array}$ \\
\hline \multirow{6}{*}{ Estágio 2} & $\begin{array}{l}\text { Escolha do método de análise } \\
\text { conjunta a ser utilizado }\end{array}$ & $\begin{array}{l}\text { Opção pela análise conjunta baseada em } \\
\text { escolhas }\end{array}$ \\
\hline & $\begin{array}{l}\text { Planejamento de estímulos: seleção e } \\
\text { definição dos atributos e níveis }\end{array}$ & $\begin{array}{l}\text { Definição dos atributos do estudo exploratório } \\
\text { em níveis de presença e ausência }\end{array}$ \\
\hline & $\begin{array}{l}\text { Especificação da forma do modelo } \\
\text { básico }\end{array}$ & $\begin{array}{l}\text { Escolha do modelo aditivo linear (utilidades } \\
\text { somadas) }\end{array}$ \\
\hline & Planejamento da coleta de dados & $\begin{array}{l}\text { Escolha do método de apresentação de } \\
\text { comparação aos pares (ordenações) }\end{array}$ \\
\hline & Criação de estímulos & $\begin{array}{l}\text { Criação das combinações de atributos, avaliados } \\
\text { dois a dois }\end{array}$ \\
\hline & $\begin{array}{l}\text { Seleção de uma medida de } \\
\text { preferência: avaliações versus } \\
\text { ordenações }\end{array}$ & $\begin{array}{l}\text { Opção pelo uso de entrevistas pessoais } \\
\text { simultâneas com registro de respostas usando } \\
\text { votadores eletrônicos }\end{array}$ \\
\hline Estágio 3 & $\begin{array}{l}\text { Definição do conjunto restritivo de } \\
\text { suposições associadas com a } \\
\text { estimação do modelo }\end{array}$ & $\begin{array}{l}\text { Estruturação do conjunto restritivo de estímulos } \\
\text { e organização da associação dos pares de } \\
\text { atributos }\end{array}$ \\
\hline \multirow[b]{2}{*}{ Estágio 4} & Seleção do método de estimação & $\begin{array}{l}\text { Opção pelo método de abordagem tradicional } \\
\text { de estimação }\end{array}$ \\
\hline & $\begin{array}{l}\text { Avaliação geral dos resultados do } \\
\text { modelo }\end{array}$ & $\begin{array}{l}\text { Avaliação através da ordenação dos atributos e } \\
\text { estabelecimento dos valores de utilidades } \\
\text { parciais }\end{array}$ \\
\hline Estágio 5 & Interpretação dos resultados & $\begin{array}{l}\text { Interpretação dos resultados individuais - } \\
\text { desagregados }\end{array}$ \\
\hline Estágio 6 & Validação dos resultados & $\begin{array}{l}\text { Realização de pré-teste interno e em ambiente } \\
\text { real }\end{array}$ \\
\hline Estágio 7 & Aplicação dos resultados conjuntos & $\begin{array}{l}\text { Segmentação dos resultados conjuntos e análise } \\
\text { de agrupamentos }\end{array}$ \\
\hline
\end{tabular}

Para o cálculo da amostra foi utilizada a técnica aleatória simples. Considerando-se um nível de confiança de 90\% e um erro amostral máximo de 5\%, obteve-se um tamanho de amostra de 202 unidades habitacionais, cuja localização foi estabelecida de forma aleatória entre as áreas, uma vez que não se pretendeu traçar perfis de usuários por bairro.

As unidades habitacionais estudadas nesse levantamento foram executadas segundo o chamado "projetoembrião", edificação composta por sala, cozinha e banheiro, com área construída total de 23,90 m².

$\mathrm{Na}$ fase de análise e reflexão da pesquisa, foram realizadas análises referentes aos benefícios, dificuldades e limitações verificados durante o processo de pesquisa, refletindo-se e discutindo-se sobre os resultados alcançados. Nessa fase, a proposta preliminar do método foi refinada, dando origem ao modelo final proposto neste trabalho.

\section{Desenvolvimento da pesquisa}

\section{Desenvolvimento da APO}

O instrumento de pesquisa utilizado na etapa de coleta de dados da APO baseou-se no "Modelo para avaliação de EHIS", proposto por Bonatto (2010), que contempla, além da caracterização do entrevistado e do nível de satisfação desse em relação a diversos aspectos funcionais da unidade habitacional e de seu entorno, questões relacionadas à sua evolução familiar e à evolução da sua moradia desde o momento da ocupação do imóvel até o presente. 
Complementarmente, foi empregada a técnica do incidente crítico (FLANAGAN, 1954), para identificar características positivas e negativas das habitações, presentes na memória dos usuários. Ainda, buscando estabelecer como as unidades habitacionais evoluíram para atender as expectativas e necessidades dos usuários, registrou-se outros dados sobre as unidades, tais como:

(a) modificações e/ou ampliações realizadas pelos usuários nas suas moradias;

(b) melhorias futuras que esses usuários pretendiam realizar;

(c) leiaute interno;

(d) posição da casa no lote; e

(e) técnicas construtivas utilizadas na fase de construção e nas eventuais intervenções realizadas.

Esses aspectos foram relacionados com o perfil dos moradores e a sua evolução familiar, como forma de compreender quais atributos eram considerados realmente importantes para as famílias beneficiadas.

Dessa forma, foi possível estabelecer alguns tipos característicos de famílias (clusters), com o objetivo de estabelecer uma classificação de acordo com as relações naturais apresentadas pela amostra. Assim, a composição familiar típica da amostra foi interpretada pela formação de clusters, utilizando o algoritmo Twostepclusters - TSC. Foram identificados, a priori, quatro tipos característicos de famílias (clusters), conforme a Tabela 1.

Além da composição típica das famílias, buscou-se também interpretar suas condições socioeconômicas, representadas por variáveis como:

(a) renda familiar;

(b) ocupação principal do responsável;

(c) recebimento ou não de benefícios do Programa Bolsa Família;

(d) condição de moradia anterior;

(e) número de moradores por habitação; e

(f) meios de transporte utilizados.

Assim, conforme a Tabela 2 , foram identificados e descritos seis agrupamentos típicos.

\section{Tabela 1 - Formação de clusters por composição familiar}

\begin{tabular}{c|c|l}
\hline Cluster & Famílias & \multicolumn{1}{c}{ Composição familiar } \\
\hline Cluster 1 & $51 \%$ & Famílias convencionais biparental e mais ou menos 2 filhos \\
\hline Cluster 2 & $7 \%$ & $\begin{array}{l}\text { Famílias chefiadas por pessoas solteiras com filhos dependentes (1,14 filho em } \\
\text { média) acompanhadas de pais, irmãos, padrastos ou avós }\end{array}$ \\
\hline Cluster 3 & $37,5 \%$ & $\begin{array}{l}\text { Família monoparental típica, chefiada por pessoas solteiras com mais ou menos 1,7 } \\
\text { filho }\end{array}$ \\
\hline Cluster 4 & $4,5 \%$ & $\begin{array}{l}\text { Famílias numerosas, mono ou biparentais, de composição complexa que abrigam } \\
\text { cerca de 3 filhos, e outros componentes familiares como genro e amigos. }\end{array}$ \\
\hline
\end{tabular}

Tabela 2 - Formação de clusters por condição socioeconômica

\begin{tabular}{c|c|l}
\hline Cluster & Famílias & \multicolumn{1}{c}{ Descrição } \\
\hline Cluster 1 & $20,3 \%$ & $\begin{array}{l}\text { Ex-proprietários, desempregados com família relativamente pequena (3,5 } \\
\text { moradores), dependente do Programa Bolsa Família }\end{array}$ \\
\hline Cluster 2 & $22,8 \%$ & $\begin{array}{l}\text { Ex-posseiros, empregados, com família média (4,2 moradores), dependente do } \\
\text { Programa Bolsa Família }\end{array}$ \\
\hline Cluster 3 & $12,9 \%$ & $\begin{array}{l}\text { Ex-posseiros, empregados, de família numerosa (5,7 moradores), dependente do } \\
\text { Programa Bolsa Família }\end{array}$ \\
\hline Cluster 4 & $6,4 \%$ & $\begin{array}{l}\text { Ex-posseiros, sem emprego, carroceiros, com família numerosa (6,4 moradores), } \\
\text { que dependem do Programa Bolsa Família. }\end{array}$ \\
\hline Cluster 5 & $16,3 \%$ & $\begin{array}{l}\text { Ex-posseiros, empregados, com família relativamente pequena (3,3 moradores), } \\
\text { independente da ajuda governamental }\end{array}$ \\
\hline Cluster 6 & $21,3 \%$ & $\begin{array}{l}\text { Ex-posseiros, aposentados, acompanhados de outros adultos (3 moradores) que } \\
\text { não recebem auxílio do Programa Bolsa Família }\end{array}$ \\
\hline
\end{tabular}


Ainda nessa fase, foi elaborada uma lista preliminar de atributos, identificados com base nas menções dos moradores, aliados àqueles atributos priorizados nas modificações realizadas ou presentes nas intenções de melhorias futuras dos respondentes.

Esses atributos foram traduzidos em requisitos dos usuários, Quadro 2, para emprego na fase de desenvolvimento.

Ainda, buscou-se estabelecer uma relação entre os clusters por condição socioeconômica e os atributos que agregavam valor aos usuários, Quadro 3. Esses atributos foram relacionados de acordo com as melhores características das residências apontadas pelos respondentes de cada cluster, bem como a principal modificação realizada e a melhoria futura prioritária pretendida.

A relação entre a situação socioeconômica dos respondentes e os atributos considerados importantes demonstra, como esperado, que quanto melhores as condições financeiras dos moradores, maior o número de modificações realizadas.

Quadro 2 - Lista preliminar de atributos e sua tradução em requisitos dos usuários

\begin{tabular}{|l|l|}
\hline \multicolumn{1}{|c|}{ Atributos agrupados } & \multicolumn{1}{c|}{ Requisitos } \\
\hline trocar porta janela & esquadrias de boa qualidade \\
\hline família & acomodar a família \\
\hline espaço & ampliar o espaço \\
\hline forro & colocar forro \\
\hline grade & colocar grade \\
\hline piso & colocar piso \\
\hline revestimentos & colocar revestimentos \\
\hline área coberta & construir área coberta \\
\hline área serviço & construir área de serviço \\
\hline banheiro & construir banheiro \\
\hline churrasqueira & construir churrasqueira \\
\hline cozinha & construir cozinha \\
\hline cozinha área serviço & construir cozinha e área serviço \\
\hline cozinha banheiro & construir banheiro \\
\hline cozinha sala & construir cozinha e sala \\
\hline depósito & construir depósito \\
\hline dois dormitórios & construir dois dormitórios \\
\hline dormitório & construir dormitório \\
\hline dormitório sala & construir dormitório e sala \\
\hline garagem & construir garagem \\
\hline comércio & construir local para comércio \\
\hline muro & construir muro \\
\hline outra casa & construir outra casa \\
\hline sala & construir sala \\
\hline segundo pavimento & construir segundo pavimento \\
\hline três dormitórios & construir três dormitórios \\
\hline acabamentos & executar acabamentos \\
\hline calçamento & executar calçamento \\
\hline pintura & executar pintura \\
\hline aparência & melhorar a aparência da casa \\
\hline qualidade construção & melhorar qualidade da construção \\
\hline segurança & morar em local seguro \\
\hline animais & possuir abrigo para animais a casa das intempéries \\
\hline telhado & \\
\hline
\end{tabular}

14 Freitas, A. C. B.; Añaña, E. da S.; Schramm, F. K. 
Quadro 3 - Relação entre clusters por condição financeira e atributos da edificação que agregam valor a esses usuários

\begin{tabular}{|c|c|c|c|c|}
\hline Cluster & Caracterização do cluster & $\begin{array}{c}\text { Modificação } \\
\text { realizada }\end{array}$ & $\begin{array}{c}\text { Melhoria } \\
\text { pretendida }\end{array}$ & $\begin{array}{c}\text { Melhor } \\
\text { característica }\end{array}$ \\
\hline Cluster 1 & $\begin{array}{l}\text { Ex-proprietários, } \\
\text { desempregados com família } \\
\text { relativamente pequena, } \\
\text { dependente do Programa } \\
\text { Bolsa Família }\end{array}$ & Construiu dormitório & $\begin{array}{l}\text { Não pretende } \\
\text { realizar melhorias }\end{array}$ & $\begin{array}{l}\text { Conforto } \\
\text { térmico e } \\
\text { espaço }\end{array}$ \\
\hline Cluster 2 & $\begin{array}{l}\text { Ex-posseiros, empregados, } \\
\text { com família média, } \\
\text { dependente do Programa } \\
\text { Bolsa Família }\end{array}$ & $\begin{array}{l}\text { Construiu dois } \\
\text { dormitórios }\end{array}$ & $\begin{array}{l}\text { Pretende colocar } \\
\text { forro }\end{array}$ & $\begin{array}{l}\text { Possuir } \\
\text { banheiro e a } \\
\text { qualidade da } \\
\text { construção }\end{array}$ \\
\hline Cluster 3 & $\begin{array}{l}\text { Ex-posseiros, empregados, de } \\
\text { família numerosa, dependente } \\
\text { do Programa Bolsa Família }\end{array}$ & Construiu dormitório & $\begin{array}{l}\text { Pretende colocar } \\
\text { forro }\end{array}$ & $\begin{array}{l}\text { Possuir } \\
\text { banheiro e } \\
\text { pátio }\end{array}$ \\
\hline Cluster 4 & $\begin{array}{l}\text { Ex-posseiros, sem emprego, } \\
\text { carroceiros, com família } \\
\text { numerosa, que dependem do } \\
\text { Programa Bolsa Família }\end{array}$ & $\begin{array}{l}\text { Construiu dormitório, } \\
\text { cozinha e alterou as } \\
\text { instalações elétricas e } \\
\text { hidráulicas }\end{array}$ & $\begin{array}{l}\text { Pretende fazer } \\
\text { acabamentos }\end{array}$ & $\begin{array}{l}\text { Considera a } \\
\text { casa boa como } \\
\text { um todo }\end{array}$ \\
\hline Cluster 5 & $\begin{array}{l}\text { Ex-posseiros, empregados, } \\
\text { com família relativamente } \\
\text { pequena, independente da } \\
\text { ajuda governamental }\end{array}$ & $\begin{array}{l}\text { Não realizou } \\
\text { modificações }\end{array}$ & $\begin{array}{l}\text { Pretende colocar } \\
\text { piso }\end{array}$ & $\begin{array}{l}\text { Conforto } \\
\text { térmico e } \\
\text { tranquilidade }\end{array}$ \\
\hline Cluster 6 & $\begin{array}{l}\text { Ex-posseiros, aposentados, } \\
\text { acompanhados de outros } \\
\text { adultos, que não recebem } \\
\text { auxílio do Programa Bolsa } \\
\text { Família }\end{array}$ & $\begin{array}{l}\text { Colocou piso, trocou } \\
\text { portas, construiu } \\
\text { dormitório }\end{array}$ & $\begin{array}{l}\text { Pretende construir } \\
\text { mais dormitórios } \\
\text { e colocar forro }\end{array}$ & $\begin{array}{l}\text { Considera a } \\
\text { casa boa como } \\
\text { um todo e lugar }\end{array}$ \\
\hline
\end{tabular}

Entretanto, chamou a atenção o fato de que os moradores em situação socioeconômica mais precária, não tendo realizado modificações relevantes, declararam não possuir nenhuma aspiração em realizar melhorias futuras ou, quando presentes, estas relacionavam-se a aspectos básicos, como colocação de forro, piso ou outros acabamentos, transparecendo uma condição de adaptação e contentamento com sua situação, frente à condição de moradia anterior à ocupação da atual habitação. Contudo, é importante ressaltar que os dados coletados não permitem realizar tais afirmações para além de possíveis hipóteses, em face da amostra restrita.

\section{Desenvolvimento do estudo de caso}

A definição do grupo de respondentes para a realização do estudo de caso deu-se através de uma parceria estabelecida com uma cooperativa habitacional, que vinha desenvolvendo alguns projetos pelo PMCMVEntidades, para famílias com renda entre 0 e 3 salários-mínimos.

Embora o meio utilizado para acessar o PMCMV-Entidades seja a organização dos futuros moradores em cooperativa, o que se percebeu é que esses futuros beneficiários não atuavam no processo como poderiam. $\mathrm{O}$ modelo de gestão adotado pela cooperativa é a combinação que compreende a idealização e gestão por lideranças comunitárias e contratação de empresa de construção (LAGO, 2012).

Segundo Silva (2014) as famílias são convidadas a ter acesso aos EHIS, e passam a pagar uma taxa administrativa à cooperativa, que administra os pagamentos individuais e cuida dos processos de despejo nos casos de inadimplência. $\mathrm{O}$ processo de concepção e projeto também se dá de uma forma muito similar ao do PMCMV-Empresas, já que uma equipe técnica contratada desenvolve o projeto dos empreendimentos (SILVA, 2014).

O grupo de respondentes do estudo de caso foi selecionado através de uma amostra qualitativa composta por famílias pertencentes à cooperativa, participando de uma reunião que possibilitou a hierarquização dos atributos previamente capturados no estudo exploratório da pesquisa, segundo as suas preferências individuais. 
Cada respondente recebeu um votador (Figura 2), dispositivo eletrônico que contém as alternativas que representam os estímulos apresentados (A e B), que podem ser selecionados para representar a escolha de cada indivíduo, de forma anônima.

No decorrer do estudo, o grupo de respondentes foi efetuando escolhas entre estímulos apresentados sequencialmente aos pares, projetados em uma tela. Essas combinações (pares) eram formadas de maneira que o primeiro estímulo de uma dada combinação era sempre igual ao último da combinação anterior (Figura 3), conforme descrito no delineamento do experimento (Estágio 3) da análise conjunta, proposto por Hair Junior et al. (2009) e adaptado ao presente trabalho.

A cada rodada de votação, o sistema eletrônico de respostas registrava simultaneamente as escolhas, exibindo instantaneamente o resultado da opção mais escolhida aos respondentes. Após o término das escolhas dos três grupos de estímulos, os dados gerados foram exportados para planilha eletrônica, registrando as preferências dos requisitos de cada respondente, individualmente.

Figura 2 - Votador eletrônico utilizado na pesquisa

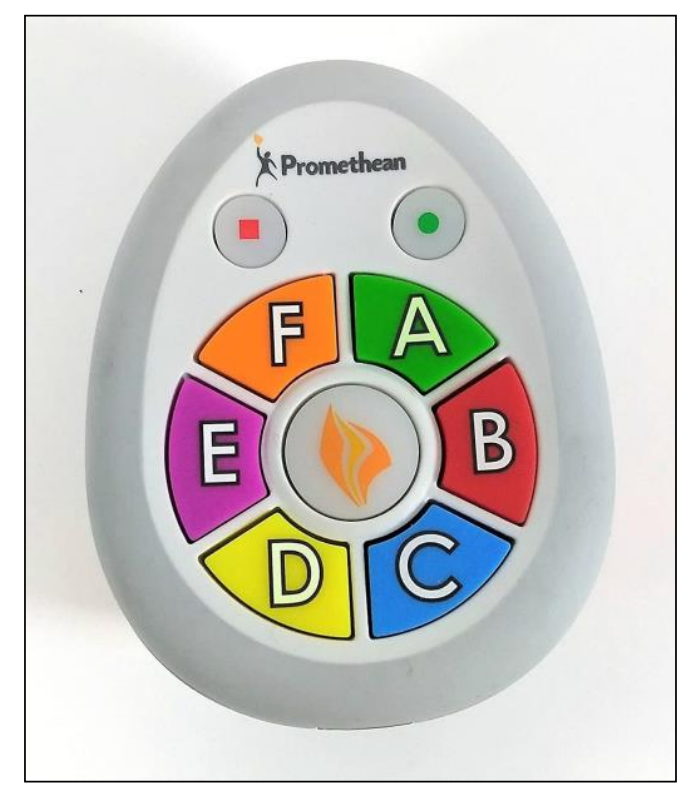

Figura 3 - Estímulos do grupo dos requisitos considerados mais importantes para a família, apresentados aos pares

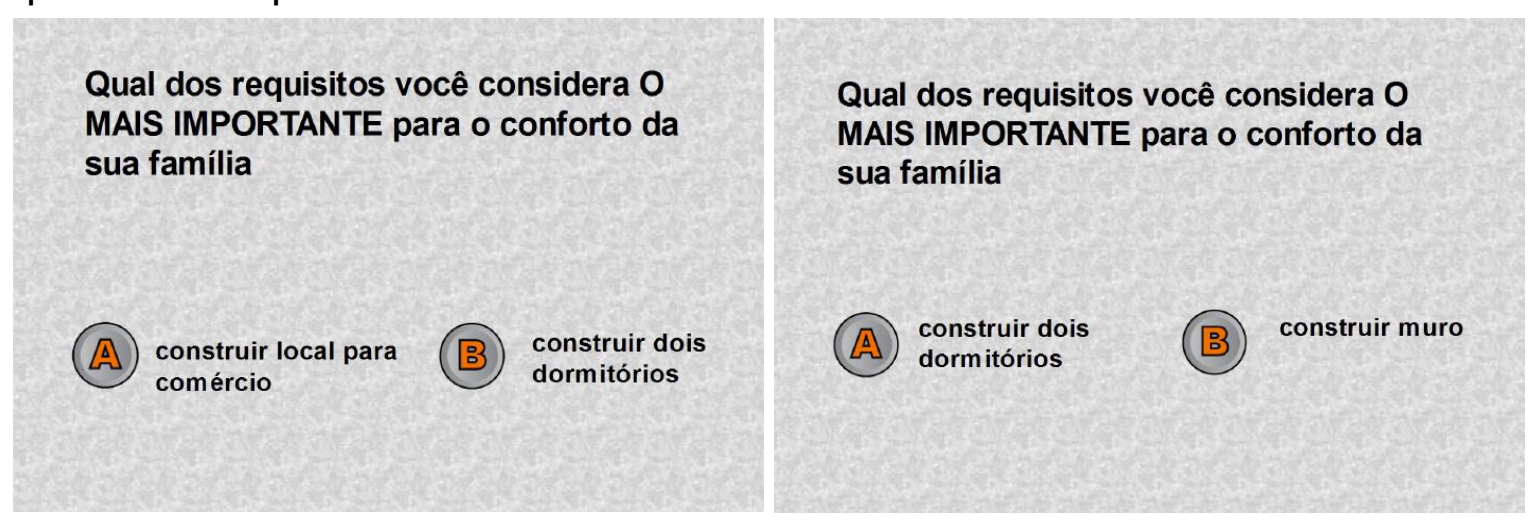

16 Freitas, A. C. B.; Añaña, E. da S.; Schramm, F. K. 
De posse dos resultados das preferencias individuais ${ }^{3}$, foi possível ordenar os conjuntos de escolha. Essa ordenação se deu de forma manual, por meio de cartões impressos, um por estímulo, de modo que o requisito preferido na primeira escolha ficou em primeiro lugar e assim por diante, como o primeiro estímulo de uma combinação sendo igual ao último da combinação anterior. Assim, foi estabelecida a sequência de escolhas, que possibilitou a hierarquização do conjunto de cada grupo de escolhas apresentado de acordo com a priorização estabelecida para cada respondente.

Após a hierarquização dos requisitos preferidos, a ordenação gerada de cada grupo de escolhas foi exportada para o software estatístico PASW/SPSS, possibilitando atribuir valores de utilidades parciais referentes à posição de ordenação do atributo, sendo maior o valor de utilidade para as primeiras escolhas e menor o valor para os atributos que ficaram nas posições mais baixas da hierarquia.

A soma linear de tais utilidades parciais estabeleceu a utilidade geral de cada atributo, permitindo a estimação do modelo básico de cada conjunto de escolhas, modelados em conjunto na próxima fase da pesquisa.

\section{Resultados da etapa de hierarquização e priorização dos requisitos dos futuros usuários de HIS}

Os requisitos foram reunidos em três grupos de escolha distintos:

(a) requisitos considerados mais importantes para as famílias;

(b) posição da casa no lote; e

(c) sentido e tipo de ampliações futuras.

A primeira etapa da hierarquização foi realizada com o conjunto de requisitos capturados como mais importantes para as famílias. Com base no conjunto de escolhas de cada respondente, foi realizado um ordenamento manual, em que os requisitos escolhidos como prioritários conforme os pares eram apresentados ocupavam as primeiras posições, enquanto aqueles não prioritários ficaram por último. Como produto dessa ordenação, obteve-se uma sequência de requisitos hierarquizados e priorizados por respondente, mostrada no Quadro 4.

$\mathrm{Na}$ segunda etapa da hierarquização, procedeu-se ao ordenamento manual do conjunto de requisitos capturados quanto à posição da casa no lote. Como na etapa anterior, os requisitos escolhidos como prioritários ocuparam as primeiras posições, e os restantes as últimas (Quadro 5).

$\mathrm{Na}$ terceira e última etapa da hierarquização, realizou-se o ordenamento manual do conjunto de requisitos capturados, quanto ao sentido e tipo de ampliações futuras (Quadro 6).

\section{Relação entre os modelos de preferência e os grupos familiares dos futuros usuários de HIS}

Nesse momento, os conjuntos de escolha, hierarquizados e priorizados na etapa anterior, foram modelados utilizando planos ortogonais estimados pelo algoritmo Orthogonal Design, pertencente ao software PASW/SPSS.

O conjunto hierarquizado dos requisitos capturados como mais importantes para as famílias foi composto por um total de 40 requisitos.

Tendo em vista a recomendação de Hair Junior et al. (2009) de que, embora a AC baseada em escolhas seja considerada mais realista e mais adequada para avaliações de combinações predeterminadas de atributos, 0 número de atributos incluídos deveria ser inferior a 10, optou-se por utilizar, para a determinação dos modelos de preferência, apenas os grupos de requisitos referentes à posição da casa no lote e sentido e tipo de ampliações futuras.

Assim, o passo seguinte consistiu na estimação das utilidades parciais dos dois grupos de requisitos hierarquizados, através da AC. O plano ortogonal foi estimado através do algoritmo Orthogonal Design, resultando em um conjunto de 20 modelos de preferência, conforme Quadro 7.

Como as prioridades dos respondentes haviam sido coletadas por grupos de requisitos, esses precisaram ser agregados para simular escolhas conjuntas. Assim, um respondente que tivesse escolhido, por exemplo,

${ }^{3}$ Cabe ressaltar que, embora as respostas fossem individuais, não houve a identificação das respostas por respondente, uma vez que o único registro quanto à origem das respostas dizia respeito ao número do votador, distribuído aleatoriamente aos participantes. 
como primeira prioridade referente ao grupo de requisitos sentido e tipo de ampliação futura, a construção de dormitório para os fundos, a partir de uma casa posicionada na divisa do lote, receberia o número 14; enquanto outro que tivesse apontado em primeiro lugar a construção de dormitório para frente, e como a melhor posição da casa o fundo do lote, receberia o número 19, por exemplo.

Os parâmetros foram transferidos ao software PASW/SPSS22, sendo que, por conveniência, a posição ideal da casa no lote foi codificada como "implantação", e o sentido e tipo de ampliações foram tratados como "melhoria".

Os quatro níveis do fator "implantação" e os cinco níveis da "melhoria", assim como as utilidades parciais de cada um, encontram-se listados na Tabela 3. Nessa tabela é possível constatar que a utilidade parcial estimada do dormitório para a frente da casa é quase vinte e duas vezes superior à utilidade da segunda opção (sala e cozinha para a lateral) e mais ainda que as opções de ampliação no sentido do fundo do lote.

Quadro 4 - Ordenamento dos 10 primeiros requisitos considerados como mais importantes para as famílias

\begin{tabular}{|c|c|l|}
\hline Ordem de resposta & $\mathbf{N}^{\mathbf{o}}$ cartão & \multicolumn{1}{|c|}{ Requisito } \\
\hline $1^{\mathbf{o}}$ & 4 & proteger a casa das intempéries \\
\hline $2^{\mathbf{o}}$ & 3 & colocar piso \\
\hline $3^{\mathbf{o}}$ & 2 & melhorar qualidade da construção \\
\hline $4^{\mathbf{0}}$ & 1 & construir garagem \\
\hline $5^{\mathbf{0}}$ & 7 & construir um dormitório \\
\hline $6^{\mathbf{0}}$ & 6 & construir cozinha e área de serviço \\
\hline $7^{\mathbf{0}}$ & 5 & colocar forro \\
\hline $8^{\mathbf{0}}$ & 14 & construir cozinha \\
\hline $9^{\mathbf{o}}$ & 13 & construir área de serviço \\
\hline $10^{\mathbf{o}}$ & 12 & construir área coberta \\
\hline
\end{tabular}

Quadro 5 - Ordenamento dos requisitos referentes à posição da casa no lote

\begin{tabular}{|c|c|l|}
\hline Ordem de resposta & $\mathbf{N}^{\mathbf{o}}$ cartão & \multicolumn{1}{c|}{ Requisito } \\
\hline $1^{\mathbf{o}}$ & 2 & No centro do lote \\
\hline $2^{\mathbf{o}}$ & 1 & Na divisa do lote \\
\hline $3^{\mathrm{o}}$ & 4 & Quase na divisa do lote \\
\hline $4^{\mathrm{o}}$ & 3 & No fundo do lote \\
\hline
\end{tabular}

Quadro 6 - Ordenamento dos requisitos referentes ao sentido e tipo de ampliações futuras

\begin{tabular}{|c|c|l|}
\hline Ordem de resposta & $\mathbf{N}^{\mathbf{o}}$ cartão & \multicolumn{1}{c|}{ Requisito } \\
\hline $1^{\mathbf{o}}$ & 4 & Dormitório e cozinha para os fundos \\
\hline $2^{\mathbf{o}}$ & 3 & Outra casa para os fundos \\
\hline $3^{\mathbf{o}}$ & 2 & Dormitórios para os fundos \\
\hline $4^{\mathbf{o}}$ & 1 & Dormitório para a frente \\
\hline $5^{\mathbf{o}}$ & 6 & Sala e cozinha para a lateral \\
\hline $6^{\mathbf{o}}$ & 5 & Dormitórios para a lateral \\
\hline $7^{\mathbf{o}}$ & 8 & Sala e dormitório para a lateral \\
\hline $8^{\mathrm{o}}$ & 7 & Sala e cozinha para os fundos \\
\hline $9^{\mathrm{o}}$ & 9 & Comércio para a lateral \\
\hline $10^{\mathrm{o}}$ & 14 & Dormitório para a frente \\
\hline $11^{\mathrm{o}}$ & 13 & Alpendre para a frente \\
\hline $12^{\mathrm{o}}$ & 12 & Cobertura para a lateral (garagem) \\
\hline $13^{\mathrm{o}}$ & 11 & Cobertura para os fundos \\
\hline $14^{\mathrm{o}}$ & 10 & Comércio para a frente \\
\hline & & \\
\hline
\end{tabular}


Quadro 7 - Modelos de preferência

\begin{tabular}{|c|c|c|}
\hline Modelo & Posição da casa no lote & Sentido e tipo de ampliação \\
\hline 1 & Quase na divisa & Dormitório e cozinha pros fundos \\
\hline 2 & Fundo do lote & Sala e cozinha para lateral \\
\hline 3 & Divisa do lote & Dormitório para frente \\
\hline 4 & Fundo do lote & Dormitório e cozinha $\mathrm{p} /$ fundos \\
\hline 5 & Quase na divisa & Dormitório para os fundos \\
\hline 6 & Centro do lote & Dormitório para frente \\
\hline 7 & Centro do lote & Sala e cozinha para lateral \\
\hline 8 & Fundo do lote & Dormitório para os fundos \\
\hline 9 & Quase na divisa & Dormitório para frente \\
\hline 10 & Centro do lote & Dormitório para os fundos \\
\hline 11 & Divisa do lote & Dormitório e cozinha para os fundos \\
\hline 12 & Fundo do lote & Outra casa para os fundos \\
\hline 13 & Quase na divisa & Outra casa para os fundos \\
\hline 14 & Divisa do lote & Dormitório para os fundos \\
\hline 15 & Centro do lote & Dormitório e cozinha para os fundos \\
\hline 16 & Quase na divisa & Sala e cozinha para lateral \\
\hline 17 & Centro do lote & Outra casa para os fundos \\
\hline 18 & Divisa do lote & Outra casa para os fundos \\
\hline 19 & Fundo do lote & Dormitório para frente \\
\hline 20 & Divisa do lote & Sala e Cozinha para lateral \\
\hline 21 & Centro do lote & Dormitório para frente \\
\hline 22 & Divisa do lote & Dormitório para frente \\
\hline
\end{tabular}

Tabela 3 - Utilidades parciais estimadas ao grupo de requisitos referentes à posição da casa no lote e ao sentido e tipo de ampliações futuras

\begin{tabular}{l|l|c|c}
\hline \multicolumn{2}{c|}{ Atributos e seus níveis } & Utilidades estimadas & Erro padrão \\
\hline \multirow{4}{*}{ Implantação } & Divisa do lote & 1,500 & 0,860 \\
\cline { 2 - 4 } & Centro do lote & 0,186 & 0,860 \\
\cline { 2 - 4 } & Fundo do lote & $-1,024$ & 0,860 \\
\cline { 2 - 4 } & Quase na divisa & $-0,662$ & 0,860 \\
\hline \multirow{4}{*}{ Melhoria } & Dormitório p/ fundos & $-0,036$ & 0,993 \\
\cline { 2 - 4 } & Dormitório + cozinha p/ fundos & $-0,619$ & 0,993 \\
\cline { 2 - 4 } & Outra casa p/ fundos & $-0,167$ & 0,993 \\
\cline { 2 - 4 } & Dormitório p/ frente & 0,786 & 0,993 \\
\cline { 2 - 4 } & Sala e cozinha p/ lateral & 0,036 & 0,993 \\
\hline Constante & & 10,500 & 0,497 \\
\hline
\end{tabular}

Nesse sentido, após modeladas as preferências, o passo seguinte consistiu na análise dos modelos, através da aplicação dos resultados conjuntos por segmentação. Os modelos de preferência gerados pelos respondentes individualmente foram agrupados de acordo com a similaridade de seus conjuntos de escolha.

Para identificar a existência de possíveis grupos com interesses similares utilizou-se a clusterização hierárquica, disponível no PASW/SPSS com plotagem de dendograma, para avaliar o melhor número de agrupamentos a formar. Constatou-se a existência de dois agrupamentos mais homogêneos, um composto por quinze respondentes e outro composto por cinco, Figura 4.

A análise de agrupamentos permitiu demonstrar que as utilidades parciais de atributos variaram entre pessoas de um mesmo grupo social, ou seja, nem todas as famílias de um mesmo grupo de futuros usuários priorizava a presença dos mesmos atributos em suas futuras moradias.

Nesse sentido, posteriormente à análise, foi possível relacionar os modelos de preferência com grupos familiares que apresentaram similaridade nas suas escolhas. Para isso, os clusters identificados foram caracterizados, com base nos dados coletados nos questionários de perfil do cliente final preenchidos pelos respondentes, utilizando o PASW/SPSS, conforme o Quadro 8. 
Figura 4 - Dendograma composto por dois agrupamentos

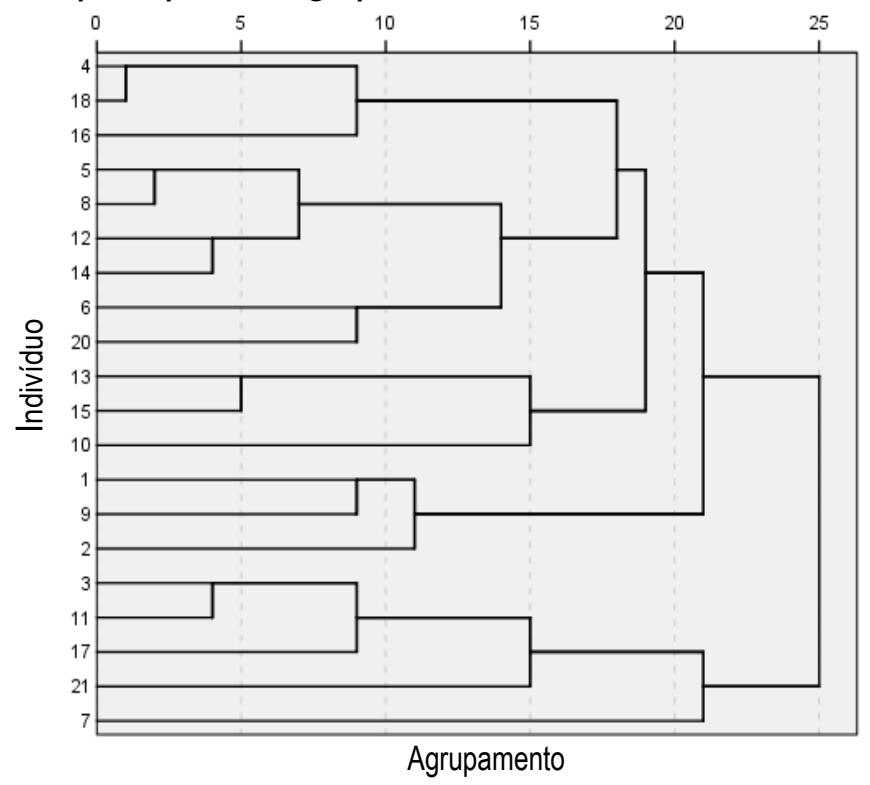

Quadro 8 - Relação dos modelos de preferência com os grupos familiares

\begin{tabular}{|c|l|l|}
\hline Cluster & \multicolumn{1}{|c|}{ Modelo de preferência } & \multicolumn{1}{c|}{ Grupos familiares } \\
\hline \multirow{3}{*}{ Cluster 1 } & $\begin{array}{l}\text { Priorizam a construção de } \\
\text { dormitório para frente em } \\
\text { casa posicionada na divisa do } \\
\text { lote }\end{array}$ & $\begin{array}{l}\text { Família com 2 a 3 moradores, responsável e seus } \\
\text { filhos, moradores de casas cedidas, com } \\
\text { responsável empregado com carteira assinada, } \\
\text { com faixa salarial até um salário-mínimo. }\end{array}$ \\
\hline \multirow{3}{*}{ Cluster 2 } & $\begin{array}{l}\text { Priorizam a construção de } \\
\text { dormitório e cozinha para os } \\
\text { fundos também em casa } \\
\text { posicionada na divisa do lote }\end{array}$ & $\begin{array}{l}\text { Família com 3 a 4 moradores, responsável e seus } \\
\text { filhos, com a presença de outros componentes, } \\
\text { moradores de casas alugadas, com responsável } \\
\text { autônomo com ganhos mensais, também, de até } \\
\text { um salário-mínimo. }\end{array}$ \\
\hline
\end{tabular}

\section{Método para captura e priorização de requisitos de usuários para subsídio da concepção e projeto de HIS}

O método proposto, composto por 5 etapas, Figura 5, destaca a sequência e os dados necessários para o desenvolvimento de cada uma delas, a descrição das atividades, bem como seus produtos.

Além da descrição das referidas etapas, faz-se uma análise dos benefícios, dificuldades e limitações da utilização da análise conjunta baseada em escolhas, no contexto dos objetivos deste trabalho.

\section{Captura de requisitos}

Esta etapa consiste em realização de uma APO, com usuários que já possuam experiência de moradia em HIS, a fim de se obter uma lista preliminar de atributos considerados como os mais importantes para seus usuários.

Esses atributos são traduzidos em requisitos, separados por grupos de conjuntos de escolha, permitindo que cada grupo de requisitos possa ser hierarquizado e priorizado pelos futuros usuários, na etapa seguinte do método.

No estudo realizado, percebeu-se que muitos atributos mencionados referiam-se a características consideradas indispensáveis a uma moradia digna, o que pode ser atribuído à natureza do projeto das unidades habitacionais foco da APO (projeto embrião) não contemplar alguns aspectos básicos, como a presença de dormitórios, por exemplo.

Assim, recomenda-se que a APO prescrita no método, quando possível, seja desenvolvida em unidades habitacionais com características similares às das unidades que serão projetadas. 
Figura 5 - Método proposto

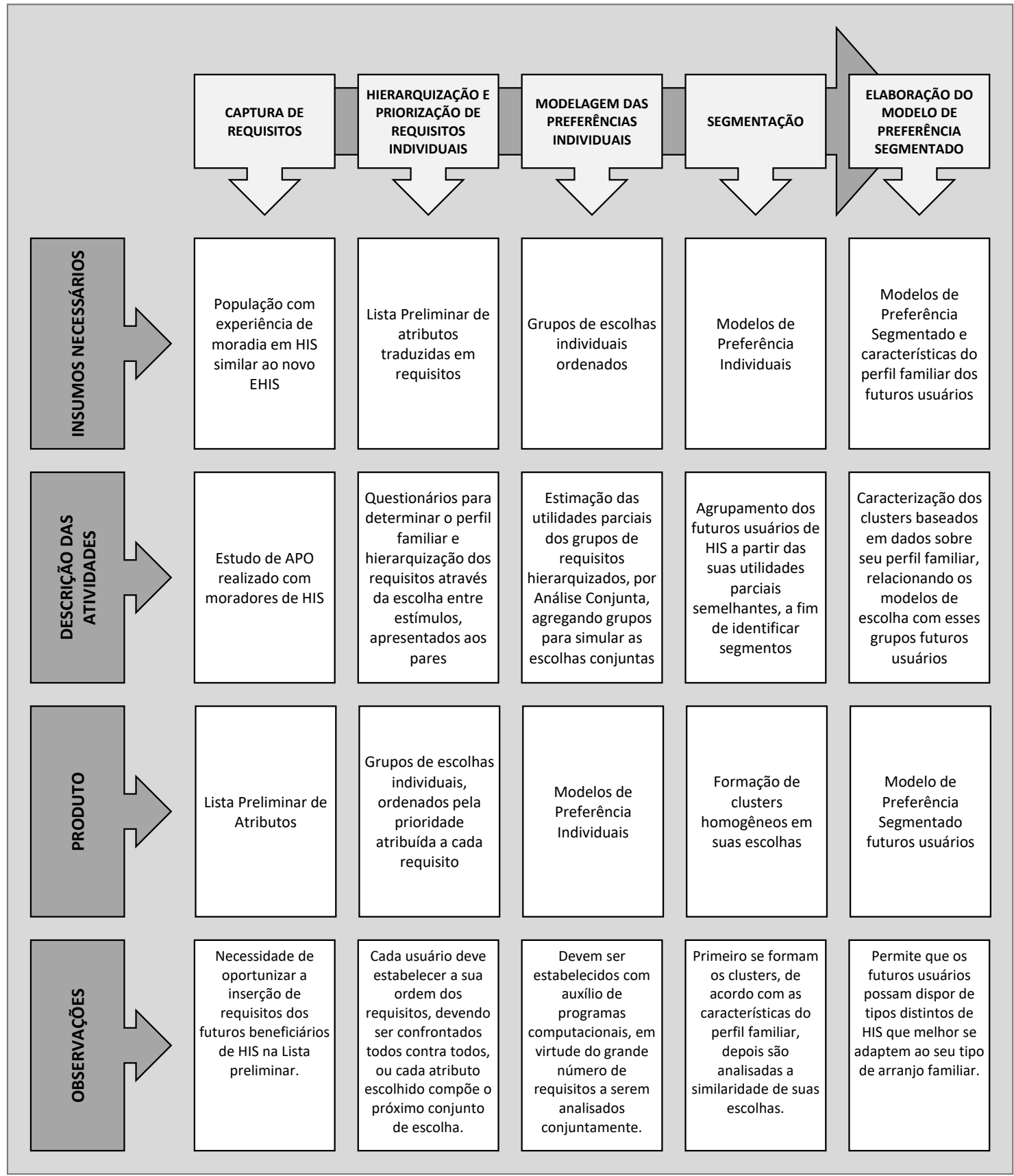

Além disso, ressalta-se a importância de utilizar, ou até mesmo desenvolver, técnicas que possibilitem a coleta dos requisitos considerados relevantes também para os futuros beneficiários, não contemplados na lista preliminar dos requisitos capturados junto aos usuários atuais.

Essa recomendação baseia-se em uma limitação do estudo aqui descrito, em que a captura de requisitos teve como base usuários de HIS, desconsiderando eventuais requisitos específicos de futuros beneficiários, e que não foram disponibilizados na etapa de hierarquização e priorização. Lima et al. (2009) corroboram essa ideia, afirmando que necessidades dos futuros moradores devem apoiar a concepção dos programas habitacionais.

Ainda, nesse sentido, Hair Junior et al. (2009) ressaltam que a importância do delineamento do projeto de $\mathrm{AC}$ é um passo crítico, pois variáveis não consideradas nessa etapa não estarão disponíveis na etapa de análise. 


\section{Hierarquização e priorização de requisitos individuais}

Nesta etapa, os requisitos capturados anteriormente são apresentados aos futuros usuários em pares, formados por todas as combinações possíveis de escolha entre os estímulos, possibilitando, assim, a coleta de dados com os respondentes de forma coletiva.

Essa hierarquização permite que cada indivíduo produza sua própria sequência de escolhas, por meio do ordenamento dos requisitos apresentados, que resultarão na sua hierarquização e consequente priorização dos mais desejados, que serão disponibilizados ao processo de concepção e projeto.

No estudo, percebeu-se que a forma de organização dos pares de escolha pode influenciar a hierarquização dos requisitos pelos respondentes. No estudo, os pares foram concebidos aleatoriamente, de forma que o último estímulo de um conjunto de escolha representasse o primeiro estímulo do par seguinte. Essa ordenação baseou-se na resposta da maioria dos respondentes, perdendo-se, dessa forma, a possibilidade de avaliar o grau de importância dada individualmente, por cada respondente, aos requisitos avaliados.

Embora esse processo tenha apresentado como vantagem a possibilidade de coletar muitas respostas simultaneamente (em torno de 20 de cada vez, limitadas pelo número de votadores), com a orientação sobre o significado de cada conjunto de estímulos realizada simultaneamente para todos, evitando escolhas equivocadas, os indivíduos cuja priorização não coincidia com a realizada pela maioria acabavam não tendo a chance de confrontar sua escolha individual com outro atributo na rodada seguinte.

Como forma de contornar essa dificuldade, a apresentação dos pares de escolha poderia acontecer de duas formas. A primeira seria a apresentação de cada alternativa contra todas as demais, ou seja, todas as combinações possíveis de escolha entre os estímulos, aplicadas aos respondentes ainda de forma coletiva. Contudo, essa opção aumentaria o número de respostas a serem coletadas, além de exigir maior trabalho para ordenação dos atributos a partir das escolhas pareadas. Hair Junior et al. (2009) alertam que pesquisas têm demonstrado que respondentes podem completar até no máximo 30 tarefas de escolha, ou seja, depois desse ponto a qualidade dos dados pode se tornar questionável.

A segunda seria que cada respondente estabelecesse sua própria sequência de escolha, através da apresentação de combinação dos pares de estímulos individualizada, ou seja, se o processo de hierarquização fosse realizado através de entrevistas individuais. Mesmo essa forma permitindo seguir uma ordem específica para cada respondente, o tempo gasto para explicar o significado de cada conjunto de escolhas a cada respondente dificilmente permitiria a coleta de uma grande quantidade de dados.

\section{Modelagem de preferências individuais}

Para a determinação dos modelos de preferências individuais, as utilidades parciais dos grupos de requisitos hierarquizados na etapa anterior podem ser estimadas através da análise conjunta. O plano ortogonal poderá ser estimado através do algoritmo Orthogonal Design, resultando um conjunto de modelos de preferência individuais.

\section{Segmentação}

A obtenção de um modelo válido de comportamento do consumidor permite o desenvolvimento de inúmeras estratégias gerenciais (BATTESINI; CATEN, 2005). Uma delas pode estar relacionada à identificação de grupos de pessoas (clusters) com preferências similares entre si e diferentes de outros grupos.

Dessa forma, na etapa de segmentação, os futuros usuários são agrupados, tendo com base grupos similares de escolhas. Nesse sentido, após a determinação dos modelos de preferência estabelecidos para cada indivíduo, são formados os clusters de respondentes, homogêneos em suas escolhas.

Nesse sentido, os conjuntos de escolha, hierarquizados e priorizados na etapa anterior, foram modelados e posteriormente os modelos de preferência foram relacionados a grupos familiares que apresentaram similaridades nas suas escolhas. Esses grupos familiares foram estabelecidos através da caracterização dos clusters formados, realizada com base nos dados coletados sobre o perfil familiar dos respondentes.

\section{Elaboração do modelo de preferência segmentado}

Os modelos de preferência deverão ser relacionados aos grupos familiares que apresentam similaridade nas suas escolhas. Essa etapa pode ser considerada como mais importantes do processo, uma vez que permitirá subsidiar o processo de concepção e projeto dos EHIS, disponibilizando modelos de preferência dos futuros usuários, adaptados às necessidades dos diferentes arranjos familiares (clusters) identificados.

22 Freitas, A. C. B.; Añaña, E. da S.; Schramm, F. K. 


\section{Conclusão}

O objetivo deste trabalho foi o de propor um método para a captura e priorização de requisitos de futuros usuários, para subsidiar o processo de concepção e projeto de habitações de interesse social, especialmente em contextos similares aos EHIS promovidos pelo PMCMV-Entidades, no qual se prevê a concessão de financiamentos a futuros usuários organizados de forma associativa por uma entidade organizadora (associação, cooperativa, sindicato, entre outras),

Para tanto, adotou-se a estratégia de pesquisa Design Science Research. A pesquisa foi dividida em quatro fases, relacionadas às etapas da Design Science Research, conforme apresentado por Vaishnavi, Kuechler e Petter (2019). O cumprimento das etapas metodológicas propostas propiciou o refinamento desse método, considerando suas limitações, discutidas na fase de análise e reflexão para cada etapa do método proposto, e já apresentadas.

A análise conjunta baseada em escolhas foi a técnica estatística selecionada, tendo em vista a possibilidade de representar as preferências de cada indivíduo, auxiliando na identificação das necessidades do usuário, priorizando-as para então traduzi-las na forma de estratégias reais (HAIR JUNIOR et al., 2009). Além disso, a maior vantagem dessa técnica é permitir medir o comportamento de preferência e escolha de um produto ainda inexistente (ORZECHOWSKI, 2004).

O modelo proposto, composto por cinco etapas:

(a) captura de requisitos;

(b) hierarquização e priorização de requisitos individuais;

(c) modelagem de preferências individuais;

(d) segmentação; e

(e) elaboração do modelo de preferência segmentado tem como principal contribuição apoiar o processo de concepção e projeto de HIS, levando em consideração as preferências de seus futuros usuários.

Especialmente, o estabelecimento dos modelos de preferência gerados a partir uma amostra de grupos familiares previamente agrupados de acordo com seus perfis permite que os futuros usuários possam dispor de tipos distintos de HIS, mais bem adaptadas a cada arranjo familiar específico.

Essa possibilidade, entretanto, para ser viabilizada deve considerar que embora a autogestão seja um pressuposto do cooperativismo presente nos discursos e práticas dos movimentos de moradia (LAGO, 2012), o projeto e a gestão desses empreendimentos são executados, preponderantemente, pela contratação, por representantes ou lideranças do grupo de interessados, de empresas de projeto e de construção, sem a efetiva participação dos futuros beneficiários no processo de tomada de decisão, como praticado pela cooperativa habitacional estudada.

Dessa forma, um maior engajamento dos futuros usuários poderia levar a uma maior valorização da conquista da casa própria, em vez de simplesmente receber uma edificação pronta, sem que tenham a oportunidade de inserir suas preferências no processo, como vem ocorrendo na maioria dos EHIS construídos atualmente.

Assim, tais considerações resultam nas seguintes recomendações para trabalhos futuros, relacionados com a proposta de um método para captura dos requisitos dos usuários finais para subsidiar o processo de concepção e projeto de HIS:

(a) avaliar e aprimorar o método proposto através de sua aplicação em uma amostra maior de respondentes;

(b) desenvolver ferramentas computacionais, através do uso de TI, que apoiem o processo de hierarquização e priorização de requisitos;

(c) investigar e/ou desenvolver métodos para a captura de requisitos de usuários que ainda não possuem experiência em HIS, mas que devem ser agregados ao processo de concepção e projeto;

(d) investigar em quais etapas do PDP das HIS a inserção dos requisitos dos usuários finais deve ocorrer;

(e) propor o gerenciamento dos requisitos dos usuários finais em conjunto com os requisitos dos demais clientes envolvidos no PDP das HIS; e

(f) desenvolver estudos com participação efetiva dos futuros moradores no processo de projeto. 


\section{Referências}

BALDAUF, J. P. Proposta de método para modelagem de requisitos de clientes de Empreendimentos Habitacionais de Interesse Social usando BIM. Porto Alegre, 2013. 167 f. Dissertação (Mestrado em Engenharia Civil) - Escola de Engenharia, Universidade Federal do Rio Grande do Sul, Porto Alegre, 2013.

BATTESINI, M.; CATEN, T. C. Análise conjunta com estimulação em duas etapas. Produto \& produção, Porto Alegre, v. 8, n. 1, p. 31-51, mar. 2005.

BLANK-FREITAS, A. C.; AÑÃ̃A, E. S.; SCHRAMM, F. K. Avaliação pós-ocupação de habitações de interesse social e a captura de requisitos do cliente final. In: SIMPÓSIO BRASILEIRO DE QUALIDADE DO PROJETO NO AMBIENTE CONSTRUIIDO, 3.; ENCONTRO DE TECNOLOGIA DE INFORMAÇÃO E COMUNICAÇÃO NA CONSTRUÇÃO, 6., Campinas, 2013. Anais [...] Campinas: ANTAC, 2013.

BONATTO, F. Proposta de um modelo para avaliação de empreendimentos habitacionais de interesse social a partir da percepção de clientes finais. Porto Alegre, 2010. Dissertação (Mestrado em Engenharia) - Escola de Engenharia, Universidade Federal do Rio Grande do Sul, Porto Alegre, 2010.

BRANDLI, L. L.; HEINECK, L. F. M. As abordagens dos modelos de preferência declarada e revelada no processo de escolha habitacional. Ambiente Construído, Porto Alegre, v. 5, n. 2, p. 61-75, abr./jun. 2005.

BRASIL. Ministério do Desenvolvimento Regional. Programa Minha Casa Minha Vida. Sistema de Gerenciamento Habitacional. Brasília, 2020. Disponível em http://sishab.mdr.gov.br/. Acesso em: 3 fev. 2020.

CAIXA ECONÔMICA FEDERAL. COTS - Caderno de Orientação Técnico Social. Brasília: Caixa Econômica Federal, abr. 2013b. Disponível em:

http://downloads.caixa.gov.br/_arquivos/trabalho_tecnico_social/manuais_orient_tecnicas/COTS_vs2_A bril2013.pdf. Acesso em: 19 maio 2013.

CAIXA ECONÔMICA FEDERAL. Minha Casa Minha Vida. 2013a Disponível em:

http://downloads.caixa.gov.br/_arquivos/habita/mcmv/CARTILHACOMPLET A.PDF. Acesso em: 9 jul. 2013.

CARVALHO, A. C. V. de; GRANJA, A. D.; SILVA, V. G. da. Use of a card game tool to capture end users' preferences 7 and add sustainability value to social housing projects. Ambiente Construído, Porto Alegre, v. 20, n. 1, p. 7-20, jan./mar. 2020.

CONCEIÇÃO, P.; IMAI, C.; URBANO, M. Captura e hierarquização de requisitos do cliente de habitação social a partir da avaliação pós-ocupação e da técnica de preferência declarada. Gestão \& Tecnologia De Projetos, v. 10, n. 1, p. 83-102, 2015.

DRESCH, A.; LACERDA, D. P.; ANTUNES JÚNIOR, J. A. V. Design Science Research: a method for science and technology advancement. New York: Springer, 2015.

ECCONIT. Consultoria Econômica. Estudo técnico dedicado à atualização das necessidades habitacionais 2004-2030: relatório final. Novembro, 2020. Disponível em: https://www.abrainc.org.br/wpcontent/uploads/2020/12/Deficit_Habitacional_-V-8-dez-2020.pdf. Acesso em: 23 nov. 2020.

FLANAGAN, J. The critical incident technique. Psychological Bulletim, Pittsburgh, v. 51, n. 4, jul. 1954.

GRANJA, A. D. et al. A natureza do valor desejado na habitação social. Ambiente Construído, Porto Alegre, v. 9, n. 2, p. 87-103, abr./jun. 2009.

HAIR JUNIOR, J. F. et al. Análise multivariada de dados. 6. ed. Porto Alegre: Bookman, 2009.

KAPP, S.; CARDOSO, A. Marco teórico da Rede Finep de Moradia e Tecnologia Social - Rede Morar T.S. Risco Revista de Pesquisa em Arquitetura e Urbanismo, n. 17, p. 94-120, primeiro semestre, 2013. Disponível em: https://www.revistas.usp.br/risco/article/view/83049. Acesso em: 6 out. 2021.

KOSKELA, L. An exploration towards a production theory and its application to construction. Helsink, 2000. 296 f. Tese (Doutorado em Tecnologia) - Technical Research Centre of Finland, Helsinki, 2000 .

KOWALTOWSKI, D. et al. Quality of life and sustainability issues as seen by the population of lowincome housing in the region of Campinas, Brazil. Habitat International, v. 30, n. 4, p. 1100-1114, 2006. 
LAGO, L. Autogestão habitacional no Brasil: utopias e contradições. Rio de Janeiro: Letra Capital: Observatório das Metrópoles, 2012.

LIMA, L. P. et al. Perceived value in socila housing projects. In: ANNUAL CONFERENCE OF THE INTERNATIONAL GROUP FOR LEAN CONSTRUCTION, 17., Taiwan, 2009. Proceedings [...] Taiwan: IGLC, 2009.

MINEIRO, E.; RODRIGUES, E. Do crédito solidário ao MCMV entidades: uma história em construção. In: LAGO, L. (org.). Autogestão habitacional no Brasil: utopias e contradições. Rio de Janeiro: Letra Capital: Observatório das Metrópoles, 2012.

MIRON, L. Gerenciamento dos requisitos dos clientes de empreendimentos Habitacionais de Interesse Social: proposta para o programa integrado entrada da cidade em Porto Alegre/RS. Porto Alegre, 2008. 350 f. Tese (Doutorado em Engenharia Civil) - Escola de Engenharia, Universidade Federal do Rio Grande do Sul, Porto Alegre, 2008.

MIRON, L.; FORMOSO, C. T. Value generation in social housing projects: a case study on the city entrance integrated program in Porto Alegre, Brazil. In: ANNUAL CONFERENCE OF THE INTERNATIONAL GROUP FOR LEAN CONSTRUCTION, 18., Israel, 2010. Proceedings [...] Israel: IGLC, 2010.

MORAES, A. F. S. Realocação de custos para o aumento do valor entregue no desenvolvimento de produtos residenciais. Campinas, 2017. 194 f. Dissertação (Mestrado em Engenharia Civil) - Faculdade de Engenharia Civil, Arquitetura e Urbanismo, Universidade Estadual de Campinas, Campinas, 2017.

ORZECHOWSKI, M. A. Measuring housing preferences using virtual reality and bayesian belief networks. Eindhoven: Tecnhische Universiteit Eindhoven, 2004.

ROMÉRO, M.; ORNSTEIN, S. Avaliação Pós-Ocupação: métodos e técnicas aplicados à habitação social. Porto Alegre: ANTAC, 2003.

SANTOS, A.; KISTMANN, V. B.; FISCHER, S. Assessing total value requirements on low income houses in Brazil. In: ANNUAL CONFERENCE ON LEAN CONSTRUCTION, 12., Copenhaguen, 2004. Proceedings [...] Copenhaguen: IGLC, 2004.

SILVA, P. M. Paulo Machado Silva, representante do Comitê Moradia e Cidadania da Empresa Brasileira de Correios e Telégrafos: entrevista [jan./2014]. Entrevistadores: Aline Campelo Blank-Freitas e Fábio Kellermann Schramm, Pelotas: UFPEL, 2014.

ULRICH, K. T.; EPPINGER, S. D. Product design and development. New York: McGraw- Hill, 2000.

VAISHNAVI, V.; KUECHLER, W.; PETTER, S. (ed.). Design science research in information systems. 2019. Disponível em: http://www.desrist.org/design-research-in-information-systems/. Acesso em: 20 jan. 2021.

VAN AKEN, J. E. Management research based on the paradigm of the design sciences: the quest for fieldtest edandgrounded technological Rules. Journalof Management Studies, v. 41, n. 2, p. 219-246, 2004.

WOODRUFF, R. B.; GARDIAL, S. Know Your Customer: new approaches to understanding customer value and satisfaction. [S.l.]: Blackwell Publishing, 1996.

YUSOFF, W. Z. W.; WEN, W. R. Analysis of the International Sustainable Building Rating Systems (SBRSs) for Sustainable Development with Special Focused on Green Building Index (GBI) Malaysia view project Developing Corporate Waqf Framework for Malaysia View project Analysis of the In. Journal of Environmental Conservation Research, v. 2, n. 1, p. 11-26, 2014.

ZINAS, B. Z.; JUSAN, M. M. Choice behaviour of housing attributes: theory and measurement. Asian Journal of Environment-Behaviour Studies, v. 2, n. 2, p.1-17, jan./mar. 2017.

\section{Agradecimentos}

À Capes e ao CNPq pela concessão de bolsas de estudos e à Finep pelo financiamento do projeto Desenvolvimento de tecnologias sociais (TS) para a construção, recuperação, manutenção e uso sustentável de moradias, especialmente habitações de interesse social, e para a redução de riscos ambientais - rede Morar/TS, do qual esta pesquisa é parte integrante. 


\section{Aline Campelo Blank Freitas}

Curso Técnico em Edificações | Instituto Federal Sul-Rio-Grandense | Praça 20 de Setembro, 455, Centro, Campus Pelotas | Pelotas - RS Brasil | CEP 96015-360 | Tel.: (53) 2123-1000 | E-mail: alineblank@gmail.com

Edar da Silva Añaña

Centro de Ciências Socio-Organizacionais | Universidade Federal de Pelotas | Rua Gomes Carneiro, 1, Porto | CEP 96610-010 | Pelotas RS - Brasil | Tel.: (53) 98405-1004 | E-mail: edaranana@gmail.com

Fábio Kellermann Schramm

Programa de Pós-Graduação em Arquitetura e Urbanismo | Universidade Federal de Pelotas | Rua Benjamin Constant, 1359, Sala 123, Centro | Peltoas - RS - Brasil | CEP 96010-020 | Tel.: (53) 3284-5510 | E-mail: fabioks@ufpel.edu.br

\section{Ambiente Construído}

Revista da Associação Nacional de Tecnologia do Ambiente Construído

Av. Osvaldo Aranha, $99-3^{\circ}$ andar, Centro

Porto Alegre - RS - Brasil

CEP $90035-190$

Telefone: +55 (51) 3308-4084

www.seer.ufrgs.br/ambienteconstruido www.scielo.br/ac

E-mail: ambienteconstruido@ufrgs.br

(c) (1) This is an open-access article distributed under the terms of the Creative Commons Attribution License.

26 Freitas, A. C. B.; Añaña, E. da S.; Schramm, F. K. 